\title{
Brief cognitive-behavioral therapy for weight loss in midlife women: a controlled study with follow-up
}

This article was published in the following Dove Press journal:

International Journal of Women's Health

II October 2012

Number of times this article has been viewed

\section{Filipa Pimenta \\ Isabel Leal \\ João Maroco \\ Catarina Ramos}

Psychology and Health Research Unit, ISPA - Instituto Universitário, Lisbon, Portugal
Correspondence: Filipa Pimenta Psychology and Health Research Unit (UIPES); ISPA - Instituto Universitário, Rua Jardim do Tabaco, 34, I |49-04 I Lisbon, Portugal Tel +35 I 2I 88I 1700 $\mathrm{Fax}+35|2| 8860954$ Email filipa_pimenta@ispa.pt
Objective: Cognitive-behavioral therapy (CBT) has proven to be effective in weight reduction. This study explores whether individual, 8-session CBT can promote weight loss in midlife women.

Methods: Anthropometric (weight, abdominal perimeter, and body mass index calculation), psychological (health-related and sexual quality of life, stress, anxiety, and depression), and behavioral measures (binge eating disorder and restrained, external, and emotional eating) were assessed at baseline (T1), posttreatment (T2), and 4-month follow-up (T3), for a total of 21 women at baseline; the CBT group $(n=11)$ and the control group $(n=10$; waiting list) were compared.

Results: Statistically significant effects that were dependent on the intervention were observed on weight $\left(F=4.402 ; P=0.035 ; \eta_{\mathrm{p}}^{2}=0.404 ; \pi=0.652\right)$ and body mass index $(F=3.804$; $\left.P=0.050 ; \eta_{\mathrm{p}}{ }^{2}=0.369 ; \pi=0.585\right)$; furthermore, marginally significant effects were observed on external eating $\left(F=2.844 ; P=0.095 ; \eta_{\mathrm{p}}{ }^{2}=0.304 ; \pi=0.461\right)$. At follow-up, women in the CBT group presented with lower weight, abdominal perimeter, body mass index, and external eating; higher health-related quality-of-life and restrained eating were also observed in this group. Most differences identified were at a marginally significant level. Moreover, at follow-up, none of the participants of the CBT group met the criteria for binge eating disorder, whereas the number of women with binge eating disorder in the control group remained the same through all three assessments.

Conclusion: An effective, though small, weight loss was achieved. Changes in quality of life were also observed. Moreover, changes in external eating behavior were successful.

Keywords: cognitive-behavioral therapy, control group, follow-up, midlife, weight loss, women

\section{Introduction}

It has been more than a decade since the World Health Organization (WHO) identified obesity as an epidemic, recognizing it as a public health threat. ${ }^{1}$ Currently, $30 \%-80 \%$ of adults in the countries of the WHO's European Region are overweight, and recent studies have shown that, in 2010, almost 150 million adults were obese. ${ }^{2}$ In the United States, current data points to a prevalence of $33.0 \%$ of adults who are overweight and $35.7 \%$ who are obese. ${ }^{3}$

Obesity is a risk factor for cardiovascular diseases, metabolic syndrome, dyslipidemia, type II diabetes, and premature death. ${ }^{4-6}$ In addition, metabolic and muscularskeletal benefits as well as brain function improvement may be attained through weight loss and physical fitness. ${ }^{6,7}$ 
Cognitive-behavioral therapy (CBT) has proven to be effective in weight reduction. ${ }^{8-11}$ However, it is not easy to achieve and maintain this weight loss. ${ }^{8,12}$

Psychological symptoms can be associated with excessive weight and obesity. Some studies have shown that anxiety, depression, ${ }^{13-15}$ and stress are strongly related to higher body mass index (BMI) and weight gain, especially in women. ${ }^{16-18}$ However, this association is not unanimous, given that in another study, anxiety and depression symptoms were not associated with the severity of overweight. ${ }^{19}$ Furthermore, and independently from the depressive mood, increased stress can predict binge eating. ${ }^{20}$ The presence of binge eating disorder (BED), as proposed by the Diagnostic and Statistical Manual of Mental Disorders-IV-TR, ${ }^{21}$ increases the likelihood of higher BMI when compared to individuals without BED. ${ }^{22}$

Research examining BED has shown that CBT can be effective in the reduction or cessation of binge eating ${ }^{23,24}$ and its decrease will promote weight reduction. ${ }^{25} \mathrm{~A}$ consequence of weight loss can be the improvement of sexual- ${ }^{26}$ and healthrelated quality of life (QoL). ${ }^{27,28}$ However, this conclusion is not unanimous. ${ }^{29}$

The objective of this study was to explore the efficacy of 8-week individual CBT in reducing weight and binge eating, as well as to investigate whether intervention promotes differences in depression, anxiety, stress, QoL levels, and eating behaviors in a sample of middle-aged women.

\section{Methods}

\section{Participants}

Twenty-one women agreed to participate in this study. The mean age of the 21 participants was 51 years $(\mathrm{M}=51.0$; $\mathrm{SD}=5.8)$ and the mean BMI was $29(\mathrm{M}=29.3 ; \mathrm{SD}=2.2)$. Table 1 describes the participants.

\section{Measures}

The sociodemographic characteristics, menopausal status, BMI, and physical exercise were evaluated through selfreported measures.

The menopausal status was defined according to Harlow et al. ${ }^{30}$ Premenopausal women did not show any changes in their menstrual cycle, perimenopausal women reported cycle variations, and postmenopausal women had a period of at least 12 months of amenorrhea.

Weight and abdominal perimeters were measured by a trained health psychologist, always using the same scale; the remaining variables were assessed through self-reported measures.
Table I Participant characterization

\begin{tabular}{|c|c|c|}
\hline Variables & $\begin{array}{l}\text { CBT group } \\
n=I I\end{array}$ & $\begin{array}{l}\text { Control } \\
\text { group (WL) } \\
n=10\end{array}$ \\
\hline \multicolumn{3}{|l|}{ Marital status } \\
\hline Married or in a relationship & 7 & 9 \\
\hline Not married or in a relationship & 4 & I \\
\hline \multicolumn{3}{|l|}{ Professional status } \\
\hline Active & 9 & 8 \\
\hline Inactive & 2 & 2 \\
\hline \multicolumn{3}{|l|}{ Educational level } \\
\hline Primary school & 2 & 1 \\
\hline Middle school & 3 & 2 \\
\hline High school & 2 & 4 \\
\hline University & 4 & 3 \\
\hline \multicolumn{3}{|l|}{ Family annual income } \\
\hline Less than 10,000 euro & 4 & 0 \\
\hline $10,00 \mid-20,000$ euro & 2 & 3 \\
\hline $20,00 \mathrm{I}-37,500$ euro & 4 & 3 \\
\hline $37,50 \mathrm{I}-70,000$ euro & 1 & 3 \\
\hline More than 70,001 euro & 0 & I \\
\hline \multicolumn{3}{|l|}{ Menopausal status } \\
\hline Premenopause & 3 & 2 \\
\hline Perimenopause & 4 & 4 \\
\hline Postmenopause & 4 & 4 \\
\hline \multicolumn{3}{|l|}{ Physical exercise } \\
\hline Yes & 4 & 3 \\
\hline No & 7 & 7 \\
\hline
\end{tabular}

Abbreviations: $\mathrm{CBT}$, cognitive-behavioral therapy; $\mathrm{WL}$, waiting list.

Binge eating disorder was explored using the Diagnostic and Statistical Manual of Mental Disorders-IV-TR ${ }^{21}$ criteria, as evidenced in the "Criteria for further study" chapter.

The instruments included the Portuguese adaptation of the Depression, Anxiety, and Stress Scales, to assess stress, anxiety, and depression symptoms; ${ }^{31}$ the Utian Quality of Life Scale, used to explore sexual- and health-related quality of life in menopausal women; ${ }^{32}$ and the Dutch Eating Behavior Questionnaire, ${ }^{33}$ to measure restrained, emotional, and external eating behaviors.

\section{Procedure}

A study on menopause and body weight was undertaken in the city of Lisbon and the participants' recruitment was done through community settings (such as schools, universities, and corporate settings) and in the gynecology department of a hospital. The vast majority of respondents who agreed to participate ( $89 \%$ of the sample) were recruited in an educational setting and were mothers and grandmothers of students (only $7 \%$ of the respondents were recruited in the hospital and $4 \%$ through enterprises). To meet the inclusion criteria, participants had to be female, literate, and between 42 and 60 years old. 
The American Psychological Association's standards on the ethical treatment of participants were followed. A written informed consent form was delivered to all participants, which explained the aims of the study, emphasizing that participation in this research was voluntary and that participants could interrupt their collaboration at any point without consequences. After giving informed consent and agreeing to participate in the research, a community sample of 1003 participants was integrated in the study.

Sociodemographic, health- and menopause-related, lifestyle, psychological, and contextual variables were collected in this cross-sectional study. Women who had participated in the cross-sectional phase were offered voluntarily enrollment in a weight loss intervention if they fulfilled the criteria for overweight or obesity.

Of the 43 women who enrolled in the intervention program, 34 had a BMI above $24.9 \mathrm{~kg} / \mathrm{m}^{2}$ (ie, were overweight or obese). These participants were contacted by telephone, and 13 women were unreachable or unable to participate.

With the support of a computer-generated randomization scheme, 11 participants were selected to undergo individual $\mathrm{CBT}$, and 10 were included in a waiting list (WL). The control group (WL) lasted for the same period as the intervention group, which was 26 weeks. During the intervention, two participants in the CBT and one in the WL dropped out. One participant of the experimental group did not complete the follow-up assessment, and one participant from the same group was not taken into consideration in the statistical analysis because she was diagnosed with an axis II mental disorder. The sample recruitment and retention along the study is presented in Figure 1.

After the 26 weeks, the nine women on the waiting list began the individual intervention and went from T1 (baseline) until T3 (4-month follow-up); however, their outcomes were not analyzed in the present study in order to maintain the independency of both groups.

Menopausal status, anthropometric measures, and psychological variables were evaluated 1 week before the intervention (or control condition) began, 1 week after it ended, and 4 months after the second assessment. T1, posttreatment (T2), and $\mathrm{T} 3$ were conducted by a different psychologist from the one who performed the intervention. Anthropometric measurements were always made using the same weight scale.

To prevent experimenter's bias, the first psychologist, who was responsible for the assessments, was told that these were done in the context of a study on menopause, without giving any further information on the different groups or

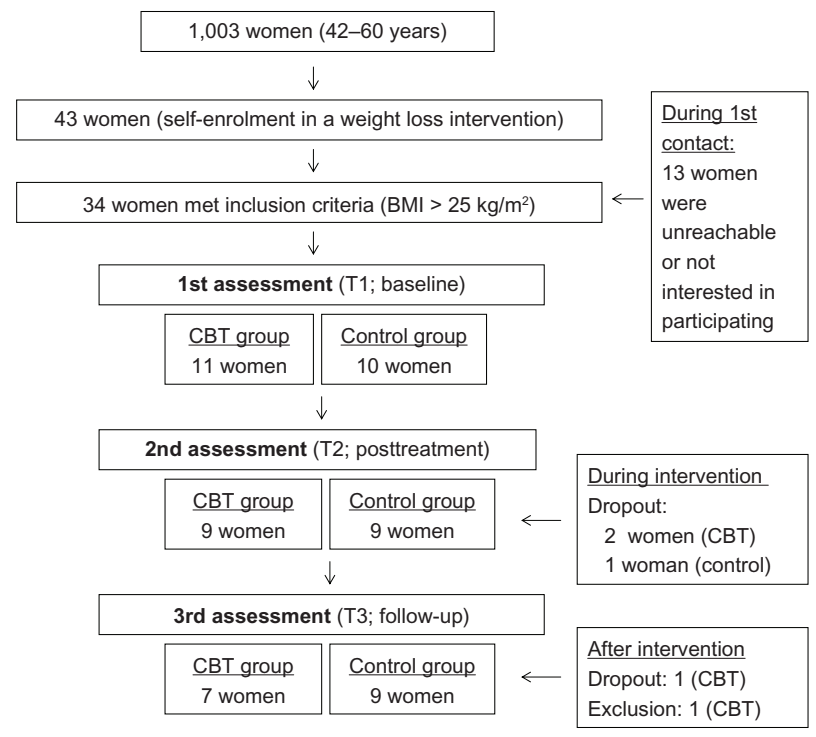

Figure I Progress of participants through the study.

specific objectives. The participants were told at the time of the recruitment that any questions regarding the intervention should be addressed to the psychologist who was responsible for the treatment, and a telephone contact was provided for that effect.

The second psychologist, who was responsible for the intervention, had formal training in CBT by the Portuguese Association on Cognitive and Behavioral Therapies.

\section{Intervention}

The cognitive-behavioral intervention was structured by two psychologists (and psychotherapists) after a literature review and based on previous interventions. It was planned as presented in Table 2. The intervention was individual, conducted in an adequate setting, and performed weekly (each session lasted 60 minutes). Regarding the materials used, in the second session, a matrix entailing seven columns (day/hour; situation; presence of excessive food ingestion; type of food; thoughts before excessive food ingestion; emotions before excessive food ingestion; other comments) was introduced and each participant began filling it in with the psychologist during the second session; the women were asked to continue filling in this report sheet at home over the following 3 weeks. During the fifth session, another matrix was delivered, a table with two columns (achieving my target weight; maintaining my present weight) and two rows (disadvantages; advantages), and used in the context of the motivation increment. This table was completed during the session and analyzed with the psychotherapist. 
Table 2 Contents of each session

\begin{tabular}{|c|c|}
\hline Session & Contents \\
\hline \multirow[t]{5}{*}{ Ist } & Relationship with the food and the body \\
\hline & Eating routines \\
\hline & Psycho-education about the consequences of excessive \\
\hline & weight and obesity \\
\hline & Motivation increment \\
\hline \multirow[t]{6}{*}{ 2nd } & Analysis of situations when there was an excessive \\
\hline & ingestion of food \\
\hline & Exploration of thoughts, emotions, and behaviors \\
\hline & subsequent to excessive food ingestion \\
\hline & Evaluation of perceived control before and during \\
\hline & excessive food ingestion \\
\hline \multirow[t]{3}{*}{3 rd } & The $A B C$ model \\
\hline & Lifestyle characteristics facilitating excessive eating \\
\hline & Trigger identification \\
\hline \multirow[t]{5}{*}{4 th } & Trigger identification and exploration of obstacles to \\
\hline & trigger management \\
\hline & Cognitive restructuring \\
\hline & Behavioral techniques \\
\hline & Physical exercise promotion \\
\hline \multirow[t]{8}{*}{5 th } & Evaluation of successful and unsuccessful \\
\hline & implementation of behavioral techniques \\
\hline & Exploration of new behavioral techniques \\
\hline & Development of mindfulness \\
\hline & Development of attention towards triggers and \\
\hline & consequent behavior (successful versus unsuccessful \\
\hline & management) \\
\hline & Motivation increment \\
\hline \multirow[t]{4}{*}{ 6th } & Assessment of successful and unsuccessful management \\
\hline & of excessive food ingestion \\
\hline & Difficulty anticipation \\
\hline & Assessment of cognitive and behavioral techniques \\
\hline \multirow[t]{2}{*}{ 7th } & Lifestyle: integrating changes \\
\hline & Redefinition of daily well-being \\
\hline \multirow[t]{2}{*}{ 8th } & Maintenance of adaptive changes made \\
\hline & Relapse prevention \\
\hline
\end{tabular}

Abbreviation: ABC, activating event, beliefs, consequences.

\section{Statistical analysis}

Data was first analyzed to identify outliers and distribution forms. No missing value imputation was made.

To explore if the two groups were homogeneous at baseline, Student's $t$-test was used to compare both conditions (experimental and control) on the anthropometric, psychological, and behavioral variables.

Comparisons between groups on the repeated measures were made using mixed repeated measures analysis of variance. A post hoc least significant difference test for mean differences was used to compare the three assessments (T1, T2, and T3) for the anthropometric, psychological, and behavioral measures in each group (CBT and waiting list).

Finally, to explore whether the amount of weight loss in the experimental group was related with educational level and family income, Spearman correlation was used.

\section{Results}

The protocol of CBT was implemented as expected, using the structure of sections previously outlined for most participants. Regarding the women who completed the program, the adherence rate to the CBT sessions varied: there was $100 \%$ adherence for 5 participants (who attended 8 sessions), $88 \%$ for a woman who attended seven sessions, and $75 \%$ for one participant (who attended six sessions).

To determine whether the participants who completed CBT differed from those on the waiting list, the two groups were compared regarding anthropometric, psychological, and behavioral variables. Table 3 presents the results; no significant differences between the two groups in the baseline assessment were observed.

To analyze whether weight and psychological changes were dependent on the condition (CBT group versus control group), multivariate tests were conducted. Hence, the variables for which variation was significantly dependent on the condition included weight $\left(F=4.402 ; P=0.035 ; \eta_{\mathrm{p}}{ }^{2}=0.404\right.$; $\pi=0.652)$ and BMI $\left(F=3.804 ; P=0.050 ; \eta_{\mathrm{p}}{ }^{2}=0.369\right.$; $\pi=0.585)$, while external eating presented a marginally significant dependence on the condition ( $F=2.844 ; P=0.095$; $\left.\eta_{\mathrm{p}}^{2}=0.304 ; \pi=0.461\right)$. Changes in abdominal perimeter $\left(F=0.703 ; P=0.513 ; \eta_{\mathrm{p}}^{2}=0.098 ; \pi=0.114\right)$, health $\mathrm{QoL}$ $\left(F=0.305 ; P=0.742 ; \eta_{\mathrm{p}}{ }^{2}=0.045 ; \pi=0.089\right)$, sexual QoL $\left(F=0.934 ; P=0.418 ; \eta_{\mathrm{p}}^{2}=0.126 ; \pi=0.177\right)$, stress $\left(F=0.271 ; P=0.767 ; \eta_{\mathrm{p}}^{2}=0.040 ; \pi=0.084\right)$, depression $\left(F=0.232 ; P=0.796 ; \eta_{\mathrm{p}}^{2}=0.034 ; \pi=0.079\right)$, anxiety $\left(F=0.762 ; P=0.486 ; \eta_{\mathrm{p}}^{2}=0.105 ; \pi=0.152\right)$, restrained eat$\operatorname{ing}\left(F=2.560 ; P=0.116 ; \eta_{\mathrm{p}}^{2}=0.283 ; \pi=0.421\right)$, and emotional eating $\left(F=1.534 ; P=0.252 ; \eta_{\mathrm{p}}^{2}=0.191 ; \pi=0.268\right)$, were not dependent on the implementation of the CBT.

Table 3 Comparison of participants placed in intervention (CBT) with participants in waiting list (WL) at baseline assessment $(\mathrm{TI})$

\begin{tabular}{ll}
\hline Variables & $\begin{array}{l}\text { Student's t-test } \\
\boldsymbol{t}(\mathbf{d f}) \boldsymbol{P}\end{array}$ \\
\hline Weight $(\mathrm{kg})$ & $-1.061(\mathrm{I}) \mathrm{ns}$ \\
Abdominal perimeter $(\mathrm{cm})$ & $-1.014(16) \mathrm{ns}$ \\
$\mathrm{BMI}\left(\mathrm{kg} / \mathrm{m}^{2}\right)$ & $-1.850(16) \mathrm{ns}$ \\
Health QoL & $0.324(16) \mathrm{ns}$ \\
Sexual QoL & $-0.579(16) \mathrm{ns}$ \\
Depression & $-0.463(16) \mathrm{ns}$ \\
Anxiety & $0.474(16) \mathrm{ns}$ \\
Stress & $0.542(16) \mathrm{ns}$ \\
Restrained eating & $-0.857(16) \mathrm{ns}$ \\
Emotional eating & $-0.548(16) \mathrm{ns}$ \\
External eating & $0.117(16) \mathrm{ns}$ \\
\hline
\end{tabular}

Abbreviations: BMI, body mass index; CBT, cognitive-behavioral therapy; ns, not significant; QoL, quality of life. 
To explore whether the variables changed during the three assessments under the same conditions, the CBT and the waiting list groups were analyzed separately after the confirmation of sphericity for all variables/groups using the Mauchly test. Results for the control group are presented in Table 4. As shown, there were no significant differences in the controlled variables.

Changes in the experimental group from the baseline assessment to follow-up are presented in Table 5. As demonstrated, significant and marginally significant differences were observed in several variables, including weight, abdominal perimeter, BMI, health QoL, and restrained and external eating (although only changes in weight, BMI, and external eating were proven to be dependent on the experimental condition).
In relation to binge eating disorder (BED), there were differences in the intervention group when comparing $\mathrm{T} 1$ (which had 2 women meeting the criteria), both with $\mathrm{T} 2$ (1 participant meeting the criteria) and with T3 (none of the participants meeting BED criteria). Regarding the waiting list group, there were no significant differences regarding BED prevalence, since the same number of participants had BED in T1, T2, and T3 (4 women with binge eating disorder and 5 without).

Additionally, within the experimental group, it was observed that the association between both family income $\left(r_{p}=0.334 ; P=0.465\right)$ and educational level $\left(r_{p}=0.335\right.$; $P=0.465)$ with the amount of weight lost was not significant.

Table 4 Waiting list: TI, T2, and T3 assessment for all variables

\begin{tabular}{|c|c|c|c|c|c|c|}
\hline Variables & $\begin{array}{l}\text { TI } \\
n=10 \\
M(S D)\end{array}$ & $\begin{array}{l}\text { T2 } \\
\mathrm{n}=9 \\
\mathrm{M}(\mathrm{SD})\end{array}$ & $\begin{array}{l}\text { T3 } \\
n=9 \\
M(S D)\end{array}$ & $\mathbf{I}$ & J & $\begin{array}{l}\text { Mean difference } \\
\text { I-J (SE) P }\end{array}$ \\
\hline \multirow[t]{3}{*}{ Weight (kg) } & $78.1(7.2)$ & $78.1(6.3)$ & $78.9(5.7)$ & TI & $\mathrm{T} 2$ & $0.022(0.56 \mathrm{I}) \mathrm{ns}$ \\
\hline & & & & & T3 & $-0.822(0.765) \mathrm{ns}$ \\
\hline & & & & T2 & T3 & $-0.844(0.492) \mathrm{ns}$ \\
\hline \multirow[t]{3}{*}{ Abdominal perimeter $(\mathrm{cm})$} & $98.5(7.0)$ & $99.5(7.0)$ & $99.0(5.8)$ & $\mathrm{TI}$ & $\mathrm{T} 2$ & $-0.989(1.508) n s$ \\
\hline & & & & & T3 & $-0.478(0.695) \mathrm{ns}$ \\
\hline & & & & $\mathrm{T} 2$ & T3 & $0.51 \mathrm{I}(1.289) \mathrm{ns}$ \\
\hline \multirow[t]{3}{*}{ BMI $\left(\mathrm{kg} / \mathrm{m}^{2}\right)$} & $31.8(2.4)$ & $31.8(2.2)$ & $32.2(2.2)$ & TI & $\mathrm{T} 2$ & $-0.01 \mathrm{I}(0.234) \mathrm{ns}$ \\
\hline & & & & & T3 & $-0.372(0.332) \mathrm{ns}$ \\
\hline & & & & $\mathrm{T} 2$ & T3 & $-0.36 \mathrm{I}(0.2 \mathrm{I} 2) \mathrm{ns}$ \\
\hline \multirow[t]{3}{*}{ Health QoL } & $2.5(0.6)$ & $2.7(0.7)$ & $2.8(0.6)$ & TI & $\mathrm{T} 2$ & $-0.175(0.138) n s$ \\
\hline & & & & & T3 & $-0.286(0.124) \mathrm{ns}$ \\
\hline & & & & $\mathrm{T} 2$ & T3 & $-0.111(0.109) \mathrm{ns}$ \\
\hline \multirow[t]{3}{*}{ Sexual QoL } & $3.3(0.7)$ & $3.1(1.0)$ & $3.1(0.9)$ & TI & $\mathrm{T} 2$ & $0.222(0.229) \mathrm{ns}$ \\
\hline & & & & & T3 & $0.222(0.176) \mathrm{ns}$ \\
\hline & & & & $\mathrm{T} 2$ & T3 & $0.000(0.157) \mathrm{ns}$ \\
\hline \multirow[t]{3}{*}{ Depression } & I.7 (0.8) & I.6 (0.6) & $1.7(0.8)$ & TI & $\mathrm{T} 2$ & $0.079(0.107) \mathrm{ns}$ \\
\hline & & & & & T3 & $0.016(0.230) \mathrm{ns}$ \\
\hline & & & & $\mathrm{T} 2$ & T3 & $-0.063(0.235) \mathrm{ns}$ \\
\hline \multirow[t]{3}{*}{ Anxiety } & $1.6(0.6)$ & $1.5(0.6)$ & I.4 (0.4) & TI & $\mathrm{T} 2$ & $0.063(0.093) \mathrm{ns}$ \\
\hline & & & & & T3 & $0.206(0.137) \mathrm{ns}$ \\
\hline & & & & $\mathrm{T} 2$ & T3 & $0.143(0.141) \mathrm{ns}$ \\
\hline \multirow[t]{3}{*}{ Stress } & $1.9(0.5)$ & $1.8(0.9)$ & $1.9(0.8)$ & TI & $\mathrm{T} 2$ & $0.079(0.160) \mathrm{ns}$ \\
\hline & & & & & T3 & $-0.016(0.198) \mathrm{ns}$ \\
\hline & & & & $\mathrm{T} 2$ & T3 & $-0.095(0.245) \mathrm{ns}$ \\
\hline \multirow[t]{3}{*}{ Restrained eating } & $3.0(0.7)$ & $2.8(0.8)$ & $2.7(0.7)$ & TI & $\mathrm{T} 2$ & $0.178(0.262) \mathrm{ns}$ \\
\hline & & & & & T3 & $0.278(0.262) \mathrm{ns}$ \\
\hline & & & & $\mathrm{T} 2$ & T3 & $0.100(0.130) n s$ \\
\hline \multirow[t]{3}{*}{ Emotional eating } & $2.7(0.8)$ & $3.0(1.0)$ & $2.8(0.9)$ & TI & $\mathrm{T} 2$ & $-0.222(0.121) \mathrm{ns}$ \\
\hline & & & & & T3 & $-0.093(0.146) \mathrm{ns}$ \\
\hline & & & & $\mathrm{T} 2$ & T3 & $0.130(0.161) \mathrm{ns}$ \\
\hline \multirow[t]{3}{*}{ External eating } & $2.8(0.4)$ & $2.8(0.6)$ & $2.9(0.7)$ & TI & $\mathrm{T} 2$ & $-0.033(0.125) \mathrm{ns}$ \\
\hline & & & & & T3 & $-0.167(0.166) \mathrm{ns}$ \\
\hline & & & & T2 & T3 & $-0.133(0.147) \mathrm{ns}$ \\
\hline
\end{tabular}

Abbreviations: BMI, body mass index; ns, not significant; QoL, quality of life; TI, baseline; T2, posttreatment; T3, follow-up. 
Table 5 CBT: TI, T2 and T3 assessment for all variables

\begin{tabular}{|c|c|c|c|c|c|c|}
\hline Variables & $\begin{array}{l}\text { TI } n=I I \\
M(S D)\end{array}$ & $\begin{array}{l}\text { T2 n = } 9 \\
M(S D)\end{array}$ & $\begin{array}{l}\text { T3 n = } 7 \\
M(S D)\end{array}$ & $\mathbf{I}$ & J & $\begin{array}{l}\text { Mean difference } \\
\text { I-J (SE) P }\end{array}$ \\
\hline \multirow[t]{3}{*}{ Weight (kg) } & $76.9(5.4)$ & $76.4(5.1)$ & $74.5(4.4)$ & TI & $\mathrm{T} 2$ & $-1.414(1.367) \mathrm{ns}$ \\
\hline & & & & & $\mathrm{T} 3$ & $1.643(0.719)^{*}$ \\
\hline & & & & $\mathrm{T} 2$ & T3 & $3.057(1.446)^{*}$ \\
\hline \multirow[t]{3}{*}{ Abdominal perimeter $(\mathrm{cm})$} & $96.5(5.9)$ & $96.1(5.5)$ & $95.0(6.0)$ & $\mathrm{TI}$ & $\mathrm{T} 2$ & $-1.143(1.716) \mathrm{ns}$ \\
\hline & & & & & T3 & 1.171 (1.917) ns \\
\hline & & & & $\mathrm{T} 2$ & T3 & $2.314(1.133)^{*}$ \\
\hline \multirow[t]{3}{*}{ BMI $\left(\mathrm{kg} / \mathrm{m}^{2}\right)$} & $30.9(2.3)$ & $30.7(2.6)$ & $29.9(2.1)$ & $\mathrm{TI}$ & $\mathrm{T} 2$ & $-0.594(0.574) \mathrm{ns}$ \\
\hline & & & & & T3 & $0.654(0.283)^{*}$ \\
\hline & & & & $\mathrm{T} 2$ & T3 & $\mathrm{I} .249(0.650) \mathrm{ns}$ \\
\hline \multirow[t]{3}{*}{ Health QoL } & $2.7(0.6)$ & $3.0(0.5)$ & $2.9(0.6)$ & $\mathrm{TI}$ & $\mathrm{T} 2$ & $-0.347(0.213) \mathrm{ns}$ \\
\hline & & & & & T3 & $-0.490(0.243)^{*}$ \\
\hline & & & & $\mathrm{T} 2$ & T3 & $-0.143(0.125) \mathrm{ns}$ \\
\hline \multirow[t]{3}{*}{ Sexual QoL } & $3.0(1.0)$ & $3.1(1.0)$ & $3.2(0.5)$ & TI & $\mathrm{T} 2$ & $-0.190(0.160) \mathrm{ns}$ \\
\hline & & & & & T3 & $-0.190(0.377) \mathrm{ns}$ \\
\hline & & & & $\mathrm{T} 2$ & $\mathrm{~T} 3$ & $0.000(0.291) \mathrm{ns}$ \\
\hline \multirow[t]{3}{*}{ Depression } & I.6 (0.7) & I.3 (0.3) & I.5 (0.6) & $\mathrm{TI}$ & $\mathrm{T} 2$ & $0.184(0.145) \mathrm{ns}$ \\
\hline & & & & & T3 & $-0.020(0.248) \mathrm{ns}$ \\
\hline & & & & $\mathrm{T} 2$ & T3 & $-0.204(0.184) \mathrm{ns}$ \\
\hline \multirow[t]{3}{*}{ Anxiety } & $1.6(0.7)$ & I.4 (0.4) & $\mathrm{I} .5(0.5)$ & TI & $\mathrm{T} 2$ & $0.150(0.152) \mathrm{ns}$ \\
\hline & & & & & $\mathrm{T} 3$ & $0.027(0.20 \mathrm{I}) \mathrm{ns}$ \\
\hline & & & & $\mathrm{T} 2$ & T3 & $-0.122(0.154) \mathrm{ns}$ \\
\hline \multirow[t]{3}{*}{ Stress } & $2.0(0.6)$ & I.6 (0.3) & $1.9(0.6)$ & TI & T2 & $0.245(0.138) \mathrm{ns}$ \\
\hline & & & & & T3 & $0.095(0.137) \mathrm{ns}$ \\
\hline & & & & $\mathrm{T} 2$ & $\mathrm{~T} 3$ & $-0.245(0.206) \mathrm{ns}$ \\
\hline \multirow[t]{3}{*}{ Restrained eating } & $2.8(0.7)$ & $3.3(0.6)$ & $3.3(0.6)$ & $\mathrm{TI}$ & $\mathrm{T} 2$ & $-0.486(0.307) \mathrm{ns}$ \\
\hline & & & & & T3 & $-0.586(0.248)^{*}$ \\
\hline & & & & $\mathrm{T} 2$ & T3 & $-0.100(0.25 \mathrm{I}) \mathrm{ns}$ \\
\hline \multirow[t]{3}{*}{ Emotional eating } & $2.8(0.7)$ & $2.4(0.7)$ & $2.6(0.7)$ & $\mathrm{TI}$ & $\mathrm{T} 2$ & $0.264(0.274) \mathrm{ns}$ \\
\hline & & & & & T3 & $0.385(0.315) \mathrm{ns}$ \\
\hline & & & & $\mathrm{T} 2$ & T3 & $0.121(0.203) \mathrm{ns}$ \\
\hline \multirow[t]{3}{*}{ External eating } & $2.9(0.6)$ & $2.7(0.4)$ & $2.7(0.4)$ & $\mathrm{TI}$ & $\mathrm{T} 2$ & $0.143(0.139) \mathrm{ns}$ \\
\hline & & & & & T3 & $0.371(0.143)^{* *}$ \\
\hline & & & & $\mathrm{T} 2$ & T3 & $0.229(0.08 \mathrm{I})^{* *}$ \\
\hline
\end{tabular}

Notes: $* P<0.10 ; * * P<0.05$.

Abbreviations: BMI, body mass index; CBT, cognitive-behavioral therapy; ns, not significant; QoL, quality of life; TI, baseline; T2, posttreatment; T3, follow-up.

\section{Discussion}

Being able to reduce weight and maintain the weight loss after the end of an intervention is not easy. ${ }^{8,12}$ In the present research, the mean weight loss evidenced at follow-up (T3) by the participants who had undergone CBT was $2.4 \mathrm{~kg}$ or $3.1 \%$ of the baseline weight. In contrast, between baseline and follow-up, the control group had a mean $1.2 \%$ increase of their initial weight (that is, a mean increment of $0.8 \mathrm{~kg}$ ).

Although this reduction was below 5\% loss, which has been pointed as a milestone for successful weight loss in other studies,${ }^{34}$ it was marginally significant and dependent on the CBT implemented. It is important to note that weight loss was only achieved at the follow-up (comparing T1 with T3, and T2 with T3), with no weight decrease being observed at the post-intervention assessment (comparing T1 with T2).
This emphasizes that since this intervention was not focused on caloric decrease or on physical activity promotion (which would likely lead to a rapid weight decrease), this treatment (which entails the identification of excessive food ingestion triggers, and the examination of the successful/unsuccessful implementation of cognitive and behavioral strategies, among others) may take more time to promote an effective change that results in weight loss. However, the loss at the follow-up assessment, 4 months after the last session, indicates that while taking longer (ie, more than the duration of the program itself) to promote a weight decrease, the effects of this intervention can be active and effective long after its implementation.

At the follow-up assessment, a marginally significant increase in restrained eating was observed in the participants 
who completed the CBT, as well as a significant decrease in external eating. Although changes in eating behavior were expected to follow this intervention, only external eating modifications were directly associated with the CBT implemented since there were no significant interactions between restrained eating and the experimental condition. Thus, this program seems to be effective in reducing the disinhibition or loss of control when facing external stimuli associated with food ingestion.

Additionally, BED also decreased in women who completed the CBT (this reduction was observed immediately after the intervention and at follow-up) when compared with the control group, in which the participants who met the criteria for BED at T1 continued meeting these criteria at follow-up. Although binge eating status and eating behaviors changed between $\mathrm{T} 2$ and $\mathrm{T} 3$, this did not reflect a successful weight reduction (that is, higher than $5 \%$ of the initial weight) after the intervention. This is congruent with the results of prior research which demonstrated that despite the decrease in binge eating behavior, successful weight loss may not be achieved. ${ }^{35}$ It has been concluded in previous studies examining cognitive-behavioral and behavioral interventions that the former is more effective in reducing binge eating while the latter promotes a greater weight loss reduction by the end of the intervention, ${ }^{11}$ evidence that supports the results of the present research. Moreover, external eating being the only behavioral change that derives from CBT, and given that both external eating and weight (although the reduction of the latter was only marginally significant and around $3.1 \%$ of initial weight) are reduced only at the follow-up assessment, it can be hypothesized that the modification of these two variables is associated.

Cognitive restraint has been associated with a significantly lower energy and fat intake, higher carbohydrate and fiber use, and higher weight reduction at 18 -month follow-up. ${ }^{36}$ This evidence supports the results of the present study: 4 months after the CBT intervention, a marginally significant weight loss was accompanied by an increase in restrained eating and a decline in external ingestion when compared to the baseline assessment, although the increment of restrained eating was not dependent on the CBT since there was no significant interaction between these variables. Other variables, not assessed in this study, may be responsible for this change, such as the increment of perceived control. This data is also in agreement with another study which pointed out that, after 2-year follow-up, participants who managed to maintain their weight also demonstrated the maintenance of the changes in their eating behaviors. ${ }^{37}$
Cognitive factors and the establishment of clear objectives, components that were approached in this brief CBT, have been evidenced as important when addressing a treatment of this kind, as they can contribute to weight regain. ${ }^{38}$

It is also important to consider that most women in this study (eight in the CBT group and eight in the control group) were in the menopause phase (perimenopause) or had already gone through menopause (postmenopause). Given that during the menopausal process there are changes in body fat distribution with a loss of lean body mass and an increase in total body fat and visceral fat, ${ }^{39-41}$ this sample's characteristics may have had an impact on the success rate observed in this research. Therefore, weight loss programs for menopausal women should consider this and target specific nutritional and physical exercise recommendations, alongside cognitive and behavioural strategies, to avoid or minimize the frequently observed weight gain during the menopausal transition and postmenopause.

The therapy format (group versus individual) has been the subject of debate. There are no significant differences in terms of the intervention's efficacy when comparing group with individual therapies. ${ }^{42,43}$ However, in a recent research with a large sample, weight reduction, as well as decrease in blood pressure, glucose, and cholesterol, was higher in a group intervention when compared with an individual approach. This may be due to the encouraging and mutually supportive environment prompted by the group format, which can make the lifestyle changes and long-term maintenance of healthier behaviors easier. ${ }^{44}$ Consequently, it is suggested that a group format could enhance the efficacy of this CBT. Furthermore, and because contents regarding physical exercise and nutrition were promoted according to general guidelines, ${ }^{45}$ it would be important in future research to include individualized nutritional and physical exercise plans as a complement to this intervention, given their efficacy in weight reduction. ${ }^{46}$

\section{Acknowledgments}

We kindly acknowledge the Portuguese Foundation for Science and Technology (FCT) for the grant SFRH/ BD/32359/2006. We also thank Raquel Oliveira for proofreading the manuscript.

\section{Disclosure}

The authors report no conflicts of interest in this work.

\section{References}

1. World Health Organization. Obesity: Preventing and Managing the Global Epidemic. Report of a WHO Consultation. Geneva: World Health Organization; 2000. Available from: http://libdoc.who.int/trs/ WHO_TRS_894.pdf. Accessed January 10, 2011. 
2. World Health Organization. The Challenge of Obesity in the WHO European Region and the Strategies for Response. In: Branca F, Nikogosian H, Lobstein T, editors. Copenhagen: World Health Organization; 2007.

3. Fryar CD, Carroll MD, Ogden CL. Prevalence of overweight, obesity, and extreme obesity among adults: United States, trends 1960-1962 through 2009-2010. Hyattssville, MD: National Center for Health Statistics; 2012. Available from: http://www.cdc.gov/nchs/data/hestat/obesity_adult_09_10/ obesity_adult_09_10.pdf. Accessed January 12, 2011.

4. Hu FB, Manson JE, Stampfer MJ, et al. Diet, lifestyle, and the risk of type 2 diabetes mellitus in women. New Engl J Med. 2001;345(11): 790-797.

5. Van Gaal LF, Mertens IL, De Block CE. Mechanisms linking obesity with cardiovascular disease. Nature. 2006;444(7121):875-880.

6. Xydakis AM, Case CC, Jones PH, et al. Adiponectin, inflammation, and the expression of the metabolic syndrome in obese individuals: the impact of rapid weight loss through caloric restriction. JClin Endocrinol Metab. 2004;89(6):2697-2703.

7. Franco OH, Karnik K, Osborne G, Ordovas JM, Catt M, Ouderaa F. Changing course in ageing research: the healthy ageing phenotype. Maturitas. 2009;63(1):13-19.

8. Cooper Z, Doll HA, Hawker DM, et al. Testing a new cognitive behavioural treatment for obesity: a randomized controlled trial with three-year follow-up. Behav Res Ther. 2010;48(8):706-713.

9. Kalodner CR, DeLucia JL. The individual and combined effects of cognitive therapy and nutrition education as additions to a behavior modification program for weight loss. Addict Behav. 1991;16(5): 255-263.

10. Mefferd K, Nichols JF, Pakiz B, Rock CL. A cognitive behavioral therapy intervention to promote weight loss improves body composition and blood lipid profiles among overweight breast cancer survivors. Breast Cancer Res Treat. 2007;104(2):145-152.

11. Munsh S, Biedert E, Meyer A, et al. A randomized comparison of cognitive-behavioral therapy and behavioural weight loss treatment for overweight individuals with binge eating disorder. Int J Eat Disord. 2007;40(2):102-113.

12. DiLillo V, Siegfried NJ, West DS. Incorporating motivational interviewing into behavioral obesity treatment. Cogn Behav Pract. 2003;10(2):120-130.

13. Anderson SE, Cohen P, Naumova EN, Must A. Association of depression and anxiety disorders with weight change in a prospective community-based study of children followed up into adulthood. Arch Pediatr Adolesc Med. 2006;160(3):285-291.

14. Cilli M, de Rosa R, Pandolfi C, et al. Quantification of sub-clinical anxiety and depression in essentially obese patients and normal-weight healthy subjects. Eat Weight Disord. 2003;8(4):319-320.

15. Luppino FS, de Wit LM, Bouvy PF, et al. Overweight, obesity, and depression: a systematic review and meta-analysis of longitudinal studies. Arch Gen Psychiatry. 2010;67(3):220-229.

16. Block JP, He Y, Zaslavsky AM, Ding L, Ayanian JZ. Psychosocial stress and change in weight among US adults. Am J Epidemiol. 2009;170(2):181-192.

17. Serlachius A, Hamer M, Wardle J. Stress and weight change in university students in the United Kingdom. Physiol Behav. 2007;92(4):548-553.

18. Smith AW, Baum A, Wing RR. Stress and weight gain in parents of cancer patients. Int J Obes. 2005;29(2):244-250.

19. Castellini G, Lapi F, Ravaldi C, et al. Eating disorder psychopathology does not predict the overweight severity in subjects seeking weight loss treatment. Compr Psychiatry. 2008;49(4):359-363.

20. Freeman LM, Gil KM. Daily stress, coping, and dietary restraint in binge eating. Int J Eat Disord. 2004;36(2):204-212.

21. American Psychiatric Association. Diagnostic and Statistical Manual of Mental Disorders - Text Review. 4th ed. Washington: American Psychiatric Association; 2000.

22. Grucza RA, Przybeck TR, Cloninger CR. Prevalence and correlates of binge eating disorder in a community sample. Compr Psychiatry. 2007;48(2):124-131.
23. Eldredge KL, Agras WS, Arnow B, et al. The effects of extending cognitive-behavioral therapy for binge eating disorder among initial treatment nonresponders. Int J Eat Disord. 1997;21(4):347-352.

24. Wilson GT, Fairburn CG. Eating disorders. In: Nathan PE, Gordon JM, editors. Guide to Treatments That Work. 3rd ed. New York: Oxford University Press; 2007:559-592.

25. Agras WS, Telch CF, Arnow B, Eldredge K, Marnell M. One-year follow-up of cognitive-behavioral therapy for obese individuals with binge eating disorder. J Consult Clin Psychol. 1997;65(2):343-347.

26. Kolotkin RL, Blinks M, Crosby RD, Østbye T, Mitchell JE, Hartley G. Improvements in sexual quality of life after moderate weight loss. Int J Impot Res. 2008;20(5):487-492.

27. Blissmer B, Riebe D, Dye G, Ruggiero L, Greene G, Marjorie M. Health-related quality of life following a clinical weight loss intervention among overweight and obese adults: intervention and 24 month follow-up effects. Health Qual Life Outcomes. 2006;4:43-50.

28. Kolotkin RL, Crosby RD, Williams GR, Hartley GG, Nicol S. The relationship between health-related quality of life and weight loss. Obes Res. 2001;9(9):564-571.

29. Maciejewski ML, Patrick DL, Williamson DF. A structured review of randomized controlled trials of weight loss showed little improvement in health-related quality of life. J Clin Epidemiol. 2005;58(6): 568-578.

30. Harlow SD, Gass M, Hall JE, et al. Executive summary of the Stages of Reproductive Aging Workshop + 10: addressing the unfinished agenda of staging reproductive aging. Menopause. 2012;19(4):387-395.

31. Pais-Ribeiro JL, Honrado A, Leal I. Contribuição para o estudo da adaptação portuguesa das escalas de ansiedade, depressão e stress (EADS) de 21 itens de Lovibond e Lovibond [Contribution for the study of the adaptation to Portuguese of the Lovibond and Lovibond's anxiety, depression and stress scales (21-item version)]. Psicologia Saúde \& Doenças. 2004;5:229-239. Portuguese.

32. Pimenta F, Leal I, Maroco J, Rosa B, Utian W. Adaptation of the Utian Quality of Life Scale to Portuguese, using a community sample of Portuguese women in pre-, peri- and post-menopause. Menopause. 2013. In press.

33. van Strien T, Frijters JER, Bergers GPA, Defares PB. The Dutch Eating Behavior Questionnaire (DEBQ) for assessment of restrained, emotional and external eating behavior. Int J Eat Disord. 1986;5(2):295-315.

34. Teixeira PJ, Going SB, Houtkooper LB, et al. Pretreatment predictors of attrition and successful weight management in women. Int $J$ Obes. 2004;28(9):1124-1133.

35. Grilo CM, Masheb RM. A randomized controlled comparison of guided self-help cognitive behavioral therapy and behavioral weight loss for binge eating disorder. Behav Res Ther. 2005;43(11):1509-1525.

36. Keränen AM, Strengell K, Savolainen MJ, Laitinen JH. Effect of weight loss intervention on the association between eating behaviour measured by TFEQ-18 and dietary intake in adults. Appetite. 2011;56(1):156-162.

37. Pekkarinen T, Takala I, Mustajoki M. Two year maintenance of weight loss after a VLCD and behavioural therapy for obesity: correlation to the scores of questionnaires measuring eating behaviour. Int $J$ Obes. 1996;20(4):332-337.

38. Cooper Z, Fairburn CG. A new cognitive behavioural approach to the treatment of obesity. Behav Res Ther. 2001;39(5):499-511.

39. Heymsfield SB, Gallagher D, Poehlman ET, et al. Menopausal changes in body composition and energy expenditure. Exp Gerontol. 1994;29(3-4):377-389.

40. Morita Y, Iwamoto I, Mizuma N, et al. Precedence of the shift of bodyfat distribution over the change in body composition after menopause. J Obstet Gynaecol Res. 2006;32(5):513-516.

41. Sternfeld B, Bhat AK, Wang H, Sharp T, Quesenberry CP. Menopause, physical activity, and body composition/fat distribution in midlife women. Med Sci Sports Exerc. 2005;37(7):1195-1202.

42. Adams SO, Grady KE, Wolk CH, Mukaida C. Weight loss: a comparison of group and individual interventions. $J$ Am Diet Assoc. 1986;86(4):485-490. 
43. Jeffery RW, Gillum R, Gerber WM, Jacobs D, Elmer PJ, Prineas RJ. Weight and sodium reduction for the prevention of hypertension: a comparison of group treatment and individual counseling. Am J Public Health. 1983;73(6):691-693.

44. Jovanović Ž, Crnčević-Orlić Ž, Štimac D, et al. Effects of obesity reduction on cardiovascular risk factors: comparison of individual and group treatment - substudy of the Croatian Healthy Weight Loss Programme. Coll Antropol. 2009;33(3):751-757.
45. World Health Organization. Global Strategy on Diet, Physical Activity and Health. Geneva: World Health Organization; 2006.

46. Wu T, Gao X, Chen M, van Dam RM. Long-term effectiveness of diet-plus-exercise interventions vs diet-only interventions for weight loss: a meta-analysis. Obes Rev. 2009;10(3):313-323.

International Journal of Women's Health

\section{Publish your work in this journal}

The International Journal of Women's Health is an international, peerreviewed open-access journal publishing original research, reports, reviews and commentaries on all aspects of women's healthcare including gynecology, obstetrics, and breast cancer. Subject areas include: Chronic conditions (migraine headaches, arthritis, osteoporosis);

\section{Dovepress}

Endocrine and autoimmune syndromes; Sexual and reproductive health; Psychological and psychosocial conditions. The manuscript management system is completely online and includes a very quick and fair peer-review system. Visit http://www.dovepress.com/ testimonials.php to read real quotes from published authors.

Submit your manuscript here: http://www.dovepress.com/international-journal-of-womens-health-journal 